\title{
Review Article \\ Biology of Beige Adipocyte and Possible Therapy for Type 2 Diabetes and Obesity
}

\author{
Fernando Lizcano ${ }^{1,2}$ and Diana Vargas ${ }^{1}$ \\ ${ }^{1}$ Center of Biomedical Research (CIBUS), Universidad de La Sabana, Chia, Colombia \\ ${ }^{2}$ Fundacion Cardioinfantil IC, Bogota, Colombia \\ Correspondence should be addressed to Fernando Lizcano; fernando.lizcano@unisabana.edu.co
}

Received 17 April 2016; Revised 12 June 2016; Accepted 26 June 2016

Academic Editor: Kazuhiro Shiizaki

Copyright (C) 2016 F. Lizcano and D. Vargas. This is an open access article distributed under the Creative Commons Attribution License, which permits unrestricted use, distribution, and reproduction in any medium, provided the original work is properly cited.

\begin{abstract}
All mammals own two main forms of fat. The classical white adipose tissue builds up energy in the form of triglycerides and is useful for preventing fatigue during periods of low caloric intake and the brown adipose tissue instead of inducing fat accumulation can produce energy as heat. Since adult humans possess significant amounts of active brown fat depots and their mass inversely correlates with adiposity, brown fat might play an important role in human obesity and energy homeostasis. New evidence suggests two types of thermogenic adipocytes with distinct developmental and anatomical features: classical brown adipocytes and beige adipocytes. Beige adipocyte has recently attracted special interest because of its ability to dissipate energy and the possible ability to differentiate itself from white adipocytes. Importantly, adult human brown adipocyte appears to be mainly composed of beigelike adipocytes, making this cell type an attractive therapeutic target for obesity and obesity-related diseases. Because many epigenetic changes can affect beige adipocyte differentiation, the knowledge of the circumstances that affect the development of beige adipocyte cells may be important for therapeutic strategies. In this review we discuss some recent observations arising from the great physiological capacity of these cells and their possible role as ways to treat obesity and diabetes mellitus type 2 .
\end{abstract}

\section{Introduction}

Diabetes mellitus type 2 (DM2) is a chronic disease, the incidence of which has increased dramatically in recent years. The consequences of diabetes are devastating due to side effects that occur in the cardiovascular system $[1,2]$. Both DM2 and obesity have become a pandemic that has begun to appear in developing countries and in developed countries the public measures to improve lifestyle habits have not reduced significantly the incidence of these diseases $[3,4]$. While one approach to DM2 is based on improving life style including exercise and reduction of weight, therapeutic advances are multiple and include drugs protecting the function of the pancreatic beta cells, increasing insulin sensitivity, rising the excretion of sugar in the urine, and modulating satiety levels via the hypothalamus $[5,6]$. The current therapeutic options for obesity are limited, given the undesirable side effects presented by many of the therapies employed to date. In addition, in many countries, only a few medications have been approved and the therapeutic effectiveness of these is not as good as expected [7]. A therapy that can reduce the accumulation of calories or increase energy expenditure to improve insulin sensitivity, reduce weight, and preserve the activity of the pancreatic beta cell is desirable but has not yet been discovered. Potential new players in the area of obesity treatment are under evaluation, and like the approach to diabetes these therapies involve drugs that enhance the balance of the satiety level in the hypothalamus and increase caloric expenditure [8-10].

Given that obesity and DM2 have precise events in common, such as energy balance, stimulation of thermogenesis, and calorie expenditure, a possible therapeutic strategy could be the manipulation of the adipose tissue that controls the balance between the accumulation of energy and the production of heat. Utilizing these parameters, from this perspective, the treatment of DM2 and obesity could be through the modulation of the physiology of the adipocyte precursors. 
TABLE 1: Characteristic of different kind of adipocyte tissue.

\begin{tabular}{|c|c|c|}
\hline White adipocytes & Brown adipocyte & $\begin{array}{c}\text { Beige adipocyte } \\
{ }^{1} \text { Cold, TZD, FGF21, IL-4, IL-6 }\end{array}$ \\
\hline Unilocular adipocyte & Multilocular adipocytes & Unilocular $\rightarrow$ multilocular \\
\hline Lipid storage $(+++)$ & Lipid storage $(+)$ & Lipid storage $(+++) \rightarrow$ Lipid storage $(++)$ \\
\hline Mitochondria (+) & Mitochondria $(+++)$ & Mitochondria $(+) \rightarrow$ mitochondria $(++)$ \\
\hline Fatty acid oxidation $(+)$ & Fatty acid oxidation $(+++)$ & Fatty acid oxidation $(+) \rightarrow$ fatty acid oxidation $(+++)$ \\
\hline Respiratory chain $(+)$ & Respiratory chain $(+++)$ & Respiratory chain $(+) \rightarrow$ respiratory chain $(+++)$ \\
\hline $\mathrm{UCP1}(-)$ & $\mathrm{UCP} 1(+++)$ & $\mathrm{UCP} 1(-) \rightarrow \mathrm{UCP} 1(+++)$ \\
\hline PGC-1 $\alpha(+)$ & PGC- $1 \alpha(+++)$ & PGC-1 $\alpha(+) \rightarrow$ PGC- $1 \alpha(+++)$ \\
\hline Markers: resistin, ASC-1, FAB4 & Markers: Zicl, Lhx8, Eval, Pdk4 & Markers: CD137, Tbx1, Cited1, Tmem26, CIDEA \\
\hline
\end{tabular}

${ }^{1}$ Conditions that stimulate the thermogenic activity of beige adipocytes.

TZD: thiazolidinedione; FGF21: fibroblast growth factor 21; UCP1: uncoupling protein 1; PGC-1 $\alpha$ : peroxisome proliferator-activated receptor-gamma coactivator alpha 1; ASC-1: adipocyte-specific cell surface protein; FABP4: fatty acid binding protein 4; Zicl: zinc finger protein 1; Lhx8: LIM/homeobox protein; Eval: epithelial V-like antigen 1; Pdk4: pyruvate dehydrogenase kinase 4; CD 137: cluster of differentiation 137; Tbxl: T-box transcription factor 1; Cited1: Cbp/P300-interacting transactivator 1; Tmem26: transmembrane protein 26; CIDEA: Cell death-inducing DFFA-like effector.

In recent years, it has been observed that the adipose tissue is more dynamic than previously believed [12]. The classical white adipose tissue (WAT) builds up energy in the form of triglycerides and is useful for preventing fatigue during periods of low caloric intake. The brown adipose tissue (BAT) is more energetically active, with a greater number of mitochondria and energy production in the form of heat, which controls homeostasis during periods of low temperature and hibernation [13]. In human adults, it is believed that white adipose tissue predominates because most of brown adipose tissue is seen only in the first few months of life [14]. However, it is obvious that an adipose tissue similar to brown adipose tissue can be seen in adults when they are subjected to low temperatures or sympathetic stimulation [15]. Despite the fact that the characteristics of this type of tissue are the same as brown adipose tissue, it is likely that these characteristics correspond to an adipose tissue variant, an energy asset that has been termed beige adipose [16-18].

While all adipocytes are mesenchymal in origin, an appreciable diversity arises during the process of differentiation; in fact BAT, in some way, has more in common with muscle cells of mesenchymal origin than with WAT [19-23]. In addition, the precursor cells of white adipose tissue can be modified with different factors to give rise to adipose tissue that is more energetically active [24, 25], Table 1 Multiple factors may modulate the process of differentiation of beige adipocytes from adipocyte precursor cells. Extracellular signals include the activation of the sympathetic nervous system, the cells of the immune system, and epigenetic variations [26] that influence the transcription of specific genes [27].

\section{The Origin of Beige Adipocyte}

The beige adipocyte is a type of adipose cell described by the ability to induce these cells to produce heat and increase energy expenditure. The beige adipocyte can be considered phenotypically as a fat cell that possesses characteristics between those of the white fat cell, an accumulator of energy, and the brown cell, which produces heat [28].
The origin of the beige adipocyte is complex; some beige adipocytes arise in epididymal white fat from precursors that express platelet-derived growth factor receptor alpha PDGFR $\alpha$, CD34, and spinocerebellar ataxia type 1 (SCA1) proteins [29-34]. Beige adipocytes may be obtained from myogenic factor 5- (Myf5-) negative precursors of inguinal white fat tissue. However, a group of these adipocytes originated from $M y f 5$-positive precursors have been reported [33]. Recently, it has been described that some beige adipocytes are Myosin Heavy Chain 11- (Myh11-) positive, which is a selective marker of smooth muscle cells [35]. All of these results indicate that beige adipocytes have a cellular origin different from the classical brown adipocyte.

Another feature of beige adipocytes is the capacity to have a flexible phenotype. While development of beige adipocytes is highly inducible from precursor cells, there is evidence that mature white fat cells can be changed to beige adipocytes through specific factors $[36,37]$. Whether this phenomenon represents a real transdifferentiation, direct transformation of white adipocyte cells to beige adipocyte cells, or corresponds to a beige adipocyte that was probably previously hidden among the white fat cells is a matter of debate [38]. One of the issues involving any special assessment in human adults is whether the adipocytes in which thermogenic properties have been detected are in reality brown adipocytes or beige adipocytes [39, 40]. According to recent studies, most of these adipocytes in the adult are considered to possess the characteristics of beige adipocytes. However, in zones like the posterior part of the neck still there are adipocytes that conserve brown phenotype [20,39, 41-43].

\section{Inducers of Beige Adipocyte}

3.1. Induction of Beige Adipocyte by Cold. The primary inducer of beige adipocytes is a reduction in temperature; this effect is obtained mainly through the stimulation of sympathetic nervous system. The general consensus is that cold stimulates a greater release of catecholamines by the nervous system, an event that stimulates thermogenesis through 


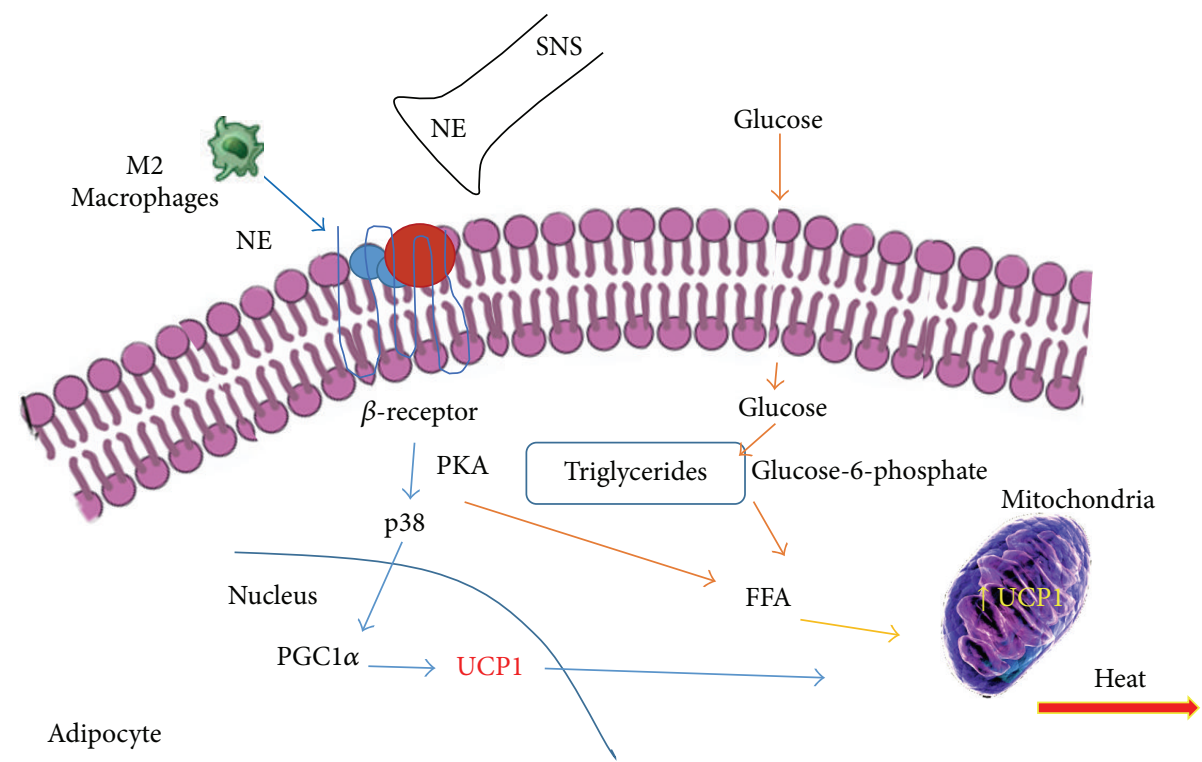

FIGURE 1: The effects of cold on the induction of thermogenic active adipocyte. The secretion of norepinephrine (NE) directly from nervous sympathetic system or indirectly through catecholamine secretion by macrophage type 2 can stimulate glucose uptake in fat cells and improve the regulation of carbohydrate. Both glucose and triglycerides are used by UCP1 protein to increase thermogenesis. FFA: free fatty acid; M2: macrophages 2, SNS: sympathetic nervous system; PKA: protein kinase A; UCP1: uncoupling protein 1; PGC-1 $\alpha$ : peroxisome proliferatoractivated receptor-gamma coactivator alpha 1 .

the activation of protein kinase A (PKA) and p38 mitogenactivated protein kinases ( $\mathrm{p}-38$ MAPK) pathways followed by the activation of uncoupling protein 1 (UCP1) and phosphorylation of the specific factors PPAR gamma coactivator 1 alpha (PGC-1 $\alpha$ ), cAMP response element-binding protein (CREB), and activating transcription factor 2 (ATF2) [14, 15, $44,45]$.

Additionally, increase of norepinephrine after cold stimulation is associated with the immune system. In fact, a greater number of type 2 macrophages with capacity to produce catecholamines have been observed in the subcutaneous fatty tissue after exposure to the cold $[18,46]$, Figure 1.

The cold as an inducer of the beige adipocyte has two functions, an initial effect that the cold has on the precursors of the adipocytes and the role that the cold plays in the mature cell during the process of beiging. While the cold effect in part may be mediated by IL- 4 and its receptor IL- $4 \mathrm{Ra}$ in the adipocyte precursors, in mature adipose cells a reduction in the IL4Ra is observed and probably this effect may include diverse mediators, including IL-33 and Met-enkephalin [47, 48].

Rich environmental stimuli (physical and social stimulation) play important roles in the dynamics of beige adipocyte development. An environmental stimulus may produce an increase in the secretion of catecholamines via the hypothalamic secretion of brain-derived neurotrophic factor (BDNF) [49]. The level of the neuron growth factor inducible VGF is increased in rich environments, and VGF appears to act as a mediating factor in the BDNF pathway [50].

3.2. Influence of Physical Exercise. Several types of exercise can increase calorie expenditure through a process of beiging.
The main mediator of this process seems to be PGC- $1 \alpha$, which influences myogenesis, mitochondria, and oxidative phosphorylation [51-53]. Some proteins produced in the muscle can influence the metabolism of the fat cell. The protein derived from fibronectin type III domain containing protein 5 , IRISIN, and the protein denominated as meteorin-like protein precursor (METRNL) can lead to the process of beiging in different ways $[54,55]$. While Irisin regulates the expression of specific genes in beige adipocytes [56], METRNL increases the activation of type 2 macrophages through eosinophils [57]. The proinflammatory interleukin IL-6 can also increase the process of beiging and induce an increase in calorie expenditure [58]. It is likely that a product of anaerobic exercise such as lactate can influence the process of beiging; this possibility requires future study [59].

3.3. Interleukins. Obesity has been considered to be a condition of slight chronic inflammation, and interleukins can influence the function of fat cells in diverse ways. Proinflammatory interleukins that are increased in obese people, such as TNF- $\alpha$, IL- $1 \beta$, and IL- 6 secreted by type I macrophages, induce undesirable effects leading to cardiovascular complications in patients with obesity [60-63]. In contrast, in thin subjects and with specific stimuli, it is possible to generate a change in the population of macrophages by increasing the number of anti-inflammatory type II macrophages [64]. These macrophages may maintain sensitivity to insulin and remodeling of the extracellular matrix [65]. Type II macrophages are activated by T-lymphocytes and eosinophils $[66,67]$. In mice, Th2 lymphocytes secrete the anti-inflammatory interleukin IL-10, which improves insulin sensitivity by blocking the action of TNF- $\alpha$. In addition, the eosinophils 
that migrate to the adipose tissue can maintain the activity of the M2 macrophages via the secretion of IL- 4 and IL-13 [68-70]. The presence of type 2 innate lymphoid cells (ILC2s), which act as $\mathrm{T}$ helper lymphocytes and produce IL-4, IL-5, and IL-13, has attracted particular interest because a reduction of these cells in adipose tissues is associated with obesity in mice and humans [71]. Recently it has been observed that IL-33 is required for the maintenance of ILC2s in the white fat cells and for the development of the beige adipose phenotype [72]. IL-33 can induce the production of IL- 4 by eosinophils and increase the production of Met-enkephalin by ILC2s $[47,73]$.

3.4. Noncoding miRNA. MicroRNAs (miRNAs) are a class of short noncoding RNAs that alter the expression of genes. Despite the fact that the main effect of miRNAs is the inhibition of the translation machinery, an increase in activity has been observed in some cases. A large number of miRNAs have demonstrated the ability to regulate the differentiation of beige adipocytes from precursor cells. However, only one group has shown a specific effect with possible clinical relevance. Some microRNAs have the ability to negatively regulate the activity of PR domain containing 16 (PRDM16), including miR-133, miR-193b, and miR-365 [74-76]. miR-93 acts as a negative regulator of adipogenesis by influencing adipocyte precursors via the modulation of sirtuin 7 (Sirt7) [77].

Other miRNAs, such as miR-196a, can increase the production of beige adipocytes by blocking the expression of homeobox $\mathrm{C} 8$ (HoxC8), which negatively regulates the activity of CCAAT/enhancer-binding protein beta $(\mathrm{C} / \mathrm{EBP}-\beta)$ [78]. The influence of miRNAs is seen in the repression of the activity of molecules such as phosphodiesterase $1 \beta(\operatorname{PDE} 1 \beta)$ and receptor interacting protein 140 (RIP140) by miR-378 and miR-30, which induces the development of beige and brown adipocytes $[79,80]$. miR-34 may suppress the differentiation of beige adipocytes by reducing the activities of sirtuin 1 (Sirt1) and fibroblast growth factor 21 (FGF21) in mice [81]. Some experiments in human adipocytes have shown that miR-26 activates the differentiation of beige adipocytes [82].

Similarly long noncoding miRNAs, such as BATE1 and Blincl, are required for the formation of beige and brown adipocytes through the production of related nucleoproteins that influence the activation of thermogenic genes [83].

3.5. Endocrine Factors and Metabolites. There are a significant number of endocrine factors that have the ability to regulate the occurrence of beige and brown adipocytes. Factors such as BMP7 [84, 85], BMP8b [86], FGF21 [87, 88], prostaglandins $[89,90]$, natriuretic peptides [91], and $\beta$ aminoisobutyric acid (BAIBA) [53] can influence the differentiation of beige adipocytes. All of these factors, which are capable of increasing caloric expenditure by various mechanisms, have protective effects regarding obesity in animals fed a high-caloric diet and improve glucose homeostasis and insulin sensitivity.

The activation of the nuclear receptor PPAR $\gamma$ has a strong effect on the differentiation of adipose cells and is involved in the differentiation of all types of fat cells. PPAR $\gamma$ agonists have been used clinically to improve insulin sensitivity; however, undesirable side effects have limited the therapeutic use of these compounds [92, 93]. Recently, selective agonists of PPAR $\gamma$ have been shown to control the expression of genes through enzymatic modifications such as phosphorylation or deacetylation [94-96]. The mechanism by which some ligands of PPAR $\gamma$ induce the transcription of genes involved in the process of differentiation of the beige adipocytes includes the activation of Sirtl, a histone deacetylase $\mathrm{NAD}^{+}$dependent protein, which might be influenced by PPAR $\gamma$ itself and combine with PRDM16 [97, 98]. It has been observed that an increase of Sirt1 in adipose tissue improves obesity by increasing thermogenesis.

Thyroid hormones induce an increase in the dedifferentiation of beige adipocytes through a direct regulation of UCP1 promoter [99]. Estrogen may affect the adipocyte cell in different ways. In brown adipocyte cell the estrogen receptor alpha stimulation (ER) can increase the expression of UCP1 by rising PGC- $1 \alpha$ coactivator through AMPk, while in white adipocyte $\mathrm{ER} \alpha$ activation by estrogen reduces lipoprotein lipase and increases beta-adrenergic receptor activity [100].

3.6. Epigenetics and Regulators of Chromatin. Covalent modifications on histones induce a change in the conformation of chromatin, which results in a change in the expression of genes. During the differentiation process of beige adipocytes, there are several factors that modify the chromatin and thus determine the function of genes that increase caloric expenditure and determine a beige adipocyte phenotype.

The histone lysine demethylases KDM4a/JMJD2a, -JMJD2c, and KDM3a/JMJDla may interfere with the differentiation of adipocytes by different mechanisms. Jmjd2a and Jmjd2c can modify the expression of genes controlled by the nuclear receptor PPARg $[101,102]$. KDM3a bides within the SWI/SNF complex in the chromatin and controls the activity of the $\beta 1$-adrenergic receptor [103]. Mice with a jhd1a knockout have an obese phenotype due to the increased oxidation of fatty acids $[104,105]$.

The histone methyltransferase EHMT1 forms a complex with PRDM16 and is required for the determination of the production of the beige lineage [106]. EHMT1 increases the production of UCP1, and the deletion of this gene causes insulin resistance and obesity in mice, while haploinsufficiency is related to obesity and insulin resistance in humans $[107,108]$.

Histone deacetylase 1 (HDAC1) negatively regulates the thermogenic program of brown adipocytes [109]. Coordination between the inhibition of $\mathrm{HDACl}$ and the activation of the histone demethylase lysine-specific demethylases (KDM6b/JMJD3a) and KDM6a/UTX activates brown adipocyte genes and prevents the appearance of obesity [110, $111]$.

The retinoblastoma protein $(\mathrm{pRb})$ is a regulator of the differentiation of mesenchymal cells to different levels [112]. A deficiency in $\mathrm{pRb}$ increases the differentiation of the mesenchymal cell precursors into the brown adipocyte lineage with a reduction in the differentiation into osteoblasts or white adipocytes [113]. In addition, a blockage of pRb activity can control the decision of adipocyte precursors to 


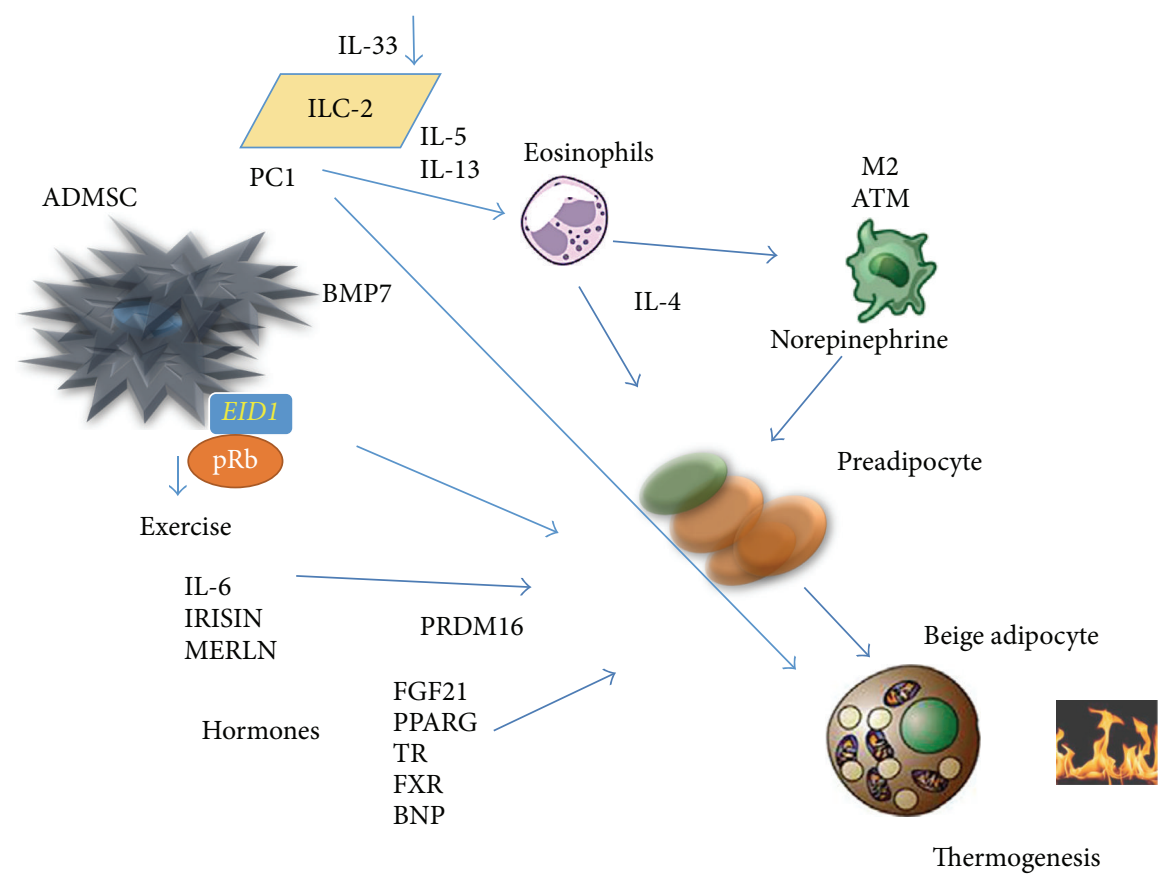

FIGURE 2: Determining factors in differentiation of beige adipose cell. The adipose mesenchymal cells can be influenced by the retinoblastoma protein $(\mathrm{pRb})$ and take decision to differentiate into fat cells when $\mathrm{pRb}$ is blocked. The EID1 protein among others can determine the differentiation of beige cells adipocytes from mesenchymal stem cells (see [11]). BMP7 triggers production of mesenchymal adipose cells to brown adipose cells. Both exercise and some hormones can increase the capacity of adipose stem cells to differentiate into beige adipocytes. Recently, it has been observed that cells of the innate immune system type 2 can secrete interleukins stimulating the production of IL4 by eosinophils and norepinephrine production through macrophage type 2 . IL-33 has the ability to activate the differentiation of beige adipocytes directly. ADMSC: adipose mesenchymal stem cell; PC1: Prohormone Convertase 1; ILC-2: group 2 innate lymphoid cells; BMP7: bone morphogenic protein 7; EID1: EP300-interacting inhibitor of differentiation 1; M2 ATM: adipose tissue macrophage 2; FGF21: fibroblastic growth factor 21; PPARg: peroxisome proliferator-activated receptor gamma; TR: thyroid receptors; FXR: farnesoid X receptor; BNP: brain natriuretic factor.

progress toward the development of beige adipocytes. EP300interacting inhibitor of differentiation 1 (EID1/CR1) can reduce the activity of $\mathrm{pRb}$ and induce differentiation to beige adipocytes [11, 114]. p107, a cell-cycle regulator that belongs to the $\mathrm{pRb}$ family, has demonstrated an important role in the decision of mesenchymal stem cells in the differentiation of beige adipocytes [115], Figure 2 .

3.7. Potential Therapeutic Use in Humans. A characteristic of white adipocyte tissue (WAT) is the capacity to change its dimensions. When an increase of caloric intake or reduction of physical activity produces positive energy balance the adipocyte cell becomes hypertrophic $[116,117]$. In obese and diabetic persons, the expansion through adipocyte hypertrophy is accompanied by a shift to an adverse adipokine secretory profile, which typically includes an elevated array of proinflammatory factors, such as TNF, IL-1 $\beta$, IL-6, IL-8, resistin, and monocyte chemoattractant protein 1 (MCP1), with a parallel reduction in anti-inflammatory factors, such as IL-10, adiponectin, and FGF21 [118]. In obesity, WAT may become severely dysfunctional and thereby fail to appropriately expand to store surplus energy. At the whole-body level, this dysfunction results in ectopic fat deposition in other tissues that regulate the metabolic homeostasis such as hepatic, pancreatic, and skeletal muscle tissues. The low inflammatory condition in the obese person reduces the insulin sensitivity and causes the majority of cardiovascular complications [13, 119].

There have been many clinical studies in human adults that suggest the beneficial effect of activating beiging from the WAT. Yoneshiro et al. [120] showed that daily 2-hour cold exposure at $17^{\circ} \mathrm{C}$ for 6 weeks resulted in increases in BAT activity and cold induced increments of energy expenditure and a concomitant decrease in body fat mass. Chondronikola et al., 2014 [121], reported that prolonged cold exposure for 5 to 8 hours was able to increase resting energy expenditure (REE) by $15 \%$, and plasma glucose $(30 \%)$ and FFA (70\%) contributed to the observed increase in REE. Glucose disposal was increased in BAT/beige and whole-body glucose disposal was significantly increased. In diabetes mellitus type 2 subjects, 10 days of cold acclimation increased peripheral insulin sensitivity by $43 \%$. Basal skeletal muscle glucose transporter type 4 (GLUT4) translocation was markedly increased and glucose uptake in skeletal muscle was increased after cold acclimation. It seems that cold exposure was able to increase energy expenditure and have beneficial effects on glucose metabolism supporting its role in treating obesity and related metabolic disorders in humans probably through an effect on beige activation. 
Adipose derived stem cells can be induced to differentiate to beige adipocytes in many ways; the large amount of research in this area suggests a great number of potential drugs in the next few years. Objectively, beige adipocytes in the adult have been shown having a beneficial effect on both the sensitivity to insulin and the reduction in body weight [122]. Although the mechanisms by which these effects occur have not been sufficiently elucidated, using the modulation of the beige adipocyte in adipose cell progenitors in the adult is clearly a therapeutic approach, especially for type 2 diabetes mellitus. Taking into account that diabetes mellitus type 2 has two key pathophysiological components, the reduction of insulin secretion and the peripheral resistance to insulin action, a change in the sensitivity to insulin mediated by an increase in the number of beige adipocytes can be a great therapeutic strategy. Additionally, a reduction in body weight may lead to a reduced load on the activity of the pancreas. Studies in mouse models have demonstrated that the manipulation of the beige adipocytes is sufficient to alter energy expenditure and homeostasis.

Some experiments have shown that a reduction in glucose levels along with an increase in insulin sensitivity can be obtained with the induction of beige/brown fat in humans [121].

Certain therapeutic effects must be evaluated before the possible clinical use of beige adipocyte induction. First, it should be determined whether the metabolic effects of the beige adipocyte are subject to an increase in UCP1 or there are alternate metabolic pathways that could improve the condition of the adipose cells [123]. It is possible that the stimulated beige adipocytes, like the brown adipocytes, not only are heat generators but also contribute to the improved metabolism of glucose and lipids through the secretion of specific factors. Another necessary aspect addresses whether there is a more specific detector for the presence of beige adipocytes in the organism; although F-FDG-PET has been improved considerably, it is desirable to develop new tools or instruments that can quantify the amount of beige adipocyte tissue in the body.

The biology of beige adipocytes is so novel that it is necessary to gain an understanding of the physiological conditions, the number of days that the cells can survive, the elements that may be necessary to maintain the functionality of this cell type, and so on.

Finally, it is important to determine the specific factors that provide plasticity to beige adipose tissue, which makes possible their differentiation from a mature white adipose cell. The process of beiging from both the precursor adipose cells as well as from the white adipose cells may be a desirable element for weight reduction.

\section{Competing Interests}

The authors declare that there are no competing interests regarding the publication of this paper.

\section{Acknowledgments}

The authors thank Jeison Garcia, Wendy Rosales, Gina Rodriguez, and other members of the laboratory for helpful suggestions. This work was supported by Colciencias Grant no. 123065740713 from 2014 and by the School of Medicine and DIN (Research Department) of Universidad de La Sabana.

\section{References}

[1] T. Wilke, S. Mueller, A. Groth et al., "Treatment-dependent and treatment-independent risk factors associated with the risk of diabetes-related events: a retrospective analysis based on 229,042 patients with type 2 diabetes mellitus," Cardiovascular Diabetology, vol. 14, no. 1, article 14, 2015.

[2] International Diabetes Federation Guideline Development Group, "Global guideline for type 2 diabetes," Diabetes Research and Clinical Practice, vol. 104, no. 1, pp. 1-52, 2014.

[3] D. Mozaffarian, T. Hao, E. B. Rimm, W. C. Willett, and F. B. $\mathrm{Hu}$, "Changes in diet and lifestyle and long-term weight gain in women and men," The New England Journal of Medicine, vol. 364, no. 25, pp. 2392-2404, 2011.

[4] M. Ezzati and E. Riboli, "Behavioral and dietary risk factors for noncommunicable diseases," The New England Journal of Medicine, vol. 369, no. 10, pp. 954-964, 2013.

[5] M. Kanat, R. A. DeFronzo, and M. A. Abdul-Ghani, "Treatment of prediabetes," World Journal of Diabetes, vol. 6, no. 12, pp. 1207-1222, 2015.

[6] C. J. Bailey, "The current drug treatment landscape for diabetes and perspectives for the future," Clinical Pharmacology and Therapeutics, vol. 98, no. 2, pp. 170-184, 2015.

[7] S. J. van Dijk, P. L. Molloy, H. Varinli et al., "Epigenetics and human obesity," International Journal of Obesity, vol. 39, no. 1, pp. 85-97, 2015.

[8] V. Yumuk, C. Tsigos, M. Fried et al., "European guidelines for obesity management in adults," Obesity Facts, vol. 8, no. 6, pp. 402-424, 2015.

[9] Y. Xia, C. M. L. Kelton, J. J. Guo, B. Bian, and P. C. Heaton, "Treatment of obesity: pharmacotherapy trends in the United States from 1999 to 2010," Obesity, vol. 23, no. 8, pp. 1721-1728, 2015.

[10] C. M. Apovian, L. J. Aronne, D. H. Bessesen et al., "Pharmacological management of obesity: an endocrine society clinical practice guideline," Journal of Clinical Endocrinology and Metabolism, vol. 100, no. 2, pp. 342-362, 2015.

[11] D. Vargas, N. Shimokawa, R. Kaneko et al., "Regulation of human subcutaneous adipocyte differentiation by EID1," Journal of Molecular Endocrinology, vol. 56, no. 2, pp. 113-122, 2016.

[12] P. Cohen and B. M. Spiegelman, "Brown and beige fat: molecular parts of a thermogenic machine," Diabetes, vol. 64, no. 7, pp. 2346-2351, 2015.

[13] E. D. Rosen and B. M. Spiegelman, "What we talk about when we talk about fat," Cell, vol. 156, no. 1-2, pp. 20-44, 2014.

[14] L. Ye, J. Wu, P. Cohen et al., "Fat cells directly sense temperature to activate thermogenesis," Proceedings of the National Academy of Sciences of the United States of America, vol. 110, no. 30, pp. 12480-12485, 2013.

[15] J. Wu, P. Cohen, and B. M. Spiegelman, "Adaptive thermogenesis in adipocytes: is beige the new brown?" Genes and Development, vol. 27, no. 3, pp. 234-250, 2013.

[16] S. Kajimura, B. M. Spiegelman, and P. Seale, "Brown and beige fat: physiological roles beyond heat generation," Cell Metabolism, vol. 22, no. 4, pp. 546-559, 2015. 
[17] J. Wu, P. Boström, L. M. Sparks et al., "Beige adipocytes are a distinct type of thermogenic fat cell in mouse and human," Cell, vol. 150, no. 2, pp. 366-376, 2012.

[18] M.-W. Lee, J. I. Odegaard, L. Mukundan et al., "Activated type 2 innate lymphoid cells regulate beige fat biogenesis," Cell, vol. 160, no. 1-2, pp. 74-87, 2015.

[19] S. Keipert and M. Jastroch, "Brite/beige fat and UCP1-is it thermogenesis?" Biochimica et Biophysica Acta (BBA)-Bioenergetics, vol. 1837, no. 7, pp. 1075-1082, 2014.

[20] M. Harms and P. Seale, "Brown and beige fat: development, function and therapeutic potential," Nature Medicine, vol. 19, no. 10, pp. 1252-1263, 2013.

[21] P. Cohen, J. D. Levy, Y. Zhang et al., "Ablation of PRDM16 and beige adipose causes metabolic dysfunction and a subcutaneous to visceral fat switch," Cell, vol. 156, no. 1-2, pp. 304-316, 2014.

[22] P. Seale, B. Bjork, W. Yang et al., "PRDM16 controls a brown fat/skeletal muscle switch," Nature, vol. 454, no. 7207, pp. 961967, 2008.

[23] J. Dempersmier and H. S. Sul, "Shades of brown: a model for thermogenic fat," Frontiers in Endocrinology, vol. 6, article 71, 2015.

[24] P. Lee, C. D. Werner, E. Kebebew, and F. S. Celi, "Functional thermogenic beige adipogenesis is inducible in human neck fat," International Journal of Obesity, vol. 38, no. 2, pp. 170-176, 2014.

[25] S. Rahman, Y. Lu, P. J. Czernik, C. J. Rosen, S. Enerback, and B. Lecka-Czernik, "Inducible brown adipose tissue, or beige fat, is anabolic for the skeleton," Endocrinology, vol. 154, no. 8, pp. 2687-2701, 2013.

[26] D. Holmes, "Epigenetics: on-off switch for obesity," Nature Reviews Endocrinology, vol. 12, no. 3, p. 125, 2016.

[27] S. Kajimura, "Engineering fat cell fate to fight obesity and metabolic diseases," The Keio Journal of Medicine, vol. 64, no. 4, p. 65, 2015.

[28] S. Y. Min, J. Kady, M. Nam et al., "Human 'brite/beige' adipocytes develop from capillary networks, and their implantation improves metabolic homeostasis in mice," Nature Medicine, vol. 22, pp. 312-318, 2016.

[29] M. L. Bonet, P. Oliver, and A. Palou, "Pharmacological and nutritional agents promoting browning of white adipose tissue," Biochimica et Biophysica Acta (BBA)-Molecular and Cell Biology of Lipids, vol. 1831, no. 5, pp. 969-985, 2013.

[30] T. Shan, X. Liang, P. Bi, P. Zhang, W. Liu, and S. Kuang, "Distinct populations of adipogenic and myogenic Myf5-lineage progenitors in white adipose tissues," Journal of Lipid Research, vol. 54, no. 8, pp. 2214-2224, 2013.

[31] J. Sanchez-Gurmaches and D. A. Guertin, "Adipocyte lineages: tracing back the origins of fat," Biochimica et Biophysica Acta (BBA)-Molecular Basis of Disease, vol. 1842, no. 3, pp. 340-351, 2014.

[32] W. Liu, T. Shan, X. Yang et al., "A heterogeneous lineage origin underlies the phenotypic and molecular differences of white and beige adipocytes," Journal of Cell Science, vol. 126, no. 16, pp. 3527-3532, 2013.

[33] J. Sanchez-Gurmaches, C.-M. Hung, C. A. Sparks, Y. Tang, H. $\mathrm{Li}$, and D. A. Guertin, "PTEN loss in the Myf5 lineage redistributes body fat and reveals subsets of white adipocytes that arise from Myf5 precursors," Cell Metabolism, vol. 16, no. 3, pp. 348-362, 2012.

[34] Y.-H. Lee, A. P. Petkova, E. P. Mottillo, and J. G. Granneman, "In vivo identification of bipotential adipocyte progenitors recruited by $\beta 3$-adrenoceptor activation and high-fat feeding," Cell Metabolism, vol. 15, no. 4, pp. 480-491, 2012.
[35] J. Z. Long, K. J. Svensson, L. Tsai et al., "A smooth muscle-like origin for beige adipocytes," Cell Metabolism, vol. 19, no. 5, pp. 810-820, 2014.

[36] G. Barbatelli, I. Murano, L. Madsen et al., "The emergence of cold-induced brown adipocytes in mouse white fat depots is determined predominantly by white to brown adipocyte transdifferentiation," American Journal of Physiology —Endocrinology and Metabolism, vol. 298, no. 6, pp. E1244-E1253, 2010.

[37] M. Rosenwald, A. Perdikari, T. Rülicke, and C. Wolfrum, "Bi-directional interconversion of brite and white adipocytes," Nature Cell Biology, vol. 15, no. 6, pp. 659-667, 2013.

[38] L. Fu, X. Zhu, F. Yi, G.-H. Liu, and J. C. Izpisua Belmonte, "Regenerative medicine: transdifferentiation in vivo," Cell Research, vol. 24, no. 2, pp. 141-142, 2014.

[39] M. Rosenwald and C. Wolfrum, "The origin and definition of brite versus white and classical brown adipocytes," Adipocyte, vol. 3, no. 1, pp. 4-9, 2014.

[40] P. Seale, "Transcriptional regulatory circuits controlling brown fat development and activation," Diabetes, vol. 64, no. 7, pp. 2369-2375, 2015.

[41] J. Wu, H. Jun, and J. R. McDermott, "Formation and activation of thermogenic fat," Trends in Genetics, vol. 31, no. 5, pp. 232238, 2015.

[42] S. Bartesaghi, S. Hallen, L. Huang et al., "Thermogenic activity of UCP1 in human white fat-derived beige adipocytes," Molecular Endocrinology, vol. 29, no. 1, pp. 130-139, 2015.

[43] S. Qian, H. Huang, and Q. Tang, "Brown and beige fat: the metabolic function, induction, and therapeutic potential," Frontiers of Medicine, vol. 9, no. 2, pp. 162-172, 2015.

[44] S. Collins, " $\beta$-Adrenoceptor signaling networks in adipocytes for recruiting stored fat and energy expenditure," Frontiers in Endocrinology, vol. 2, article 102, 2012.

[45] I. Murano, G. Barbatelli, A. Giordano, and S. Cinti, "Noradrenergic parenchymal nerve fiber branching after cold acclimatisation correlates with brown adipocyte density in mouse adipose organ," Journal of Anatomy, vol. 214, no. 1, pp. 171-178, 2009.

[46] Y. Qiu, K. D. Nguyen, J. I. Odegaard et al., "Eosinophils and type 2 cytokine signaling in macrophages orchestrate development of functional beige fat," Cell, vol. 157, no. 6, pp. 1292-1308, 2014.

[47] J. R. Brestoff, B. S. Kim, S. A. Saenz et al., "Group 2 innate lymphoid cells promote beiging of white adipose tissue and limit obesity," Nature, vol. 519, no. 7542, pp. 242-246, 2015.

[48] D. Vargas, W. Rosales, and F. Lizcano, "Modifications of human subcutaneous ADMSC after PPAR $\gamma$ activation and cold exposition," Stem Cells International, vol. 2015, Article ID 196348, 8 pages, 2015.

[49] L. Cao, E. Y. Choi, X. Liu et al., "White to brown fat phenotypic switch induced by genetic and environmental activation of a hypothalamic-adipocyte axis," Cell Metabolism, vol. 14, no. 3, pp. 324-338, 2011.

[50] G. D. Foglesong, W. Huang, X. Liu et al., "Role of hypothalamic VGF in energy balance and metabolic adaption to environmental enrichment in mice," Endocrinology, vol. 157, no. 3, pp. 983996, 2016.

[51] Z. Luo, L. Ma, Z. Zhao et al., "TRPV1 activation improves exercise endurance and energy metabolism through PGC- $1 \alpha$ upregulation in mice," Cell Research, vol. 22, no. 3, pp. 551-564, 2012.

[52] P. Boström, J. Wu, M. P. Jedrychowski et al., "A PGC1- $\alpha$ dependent myokine that drives brown-fat-like development of white fat and thermogenesis," Nature, vol. 481, no. 7382, pp. 463-468, 2012. 
[53] L. D. Roberts, P. Boström, J. F. O’Sullivan et al., “ $\beta$-Aminoisobutyric acid induces browning of white fat and hepatic $\beta$-oxidation and is inversely correlated with cardiometabolic risk factors," Cell Metabolism, vol. 19, no. 1, pp. 96-108, 2014.

[54] M. P. Jedrychowski, C. D. Wrann, J. A. Paulo et al., "Detection and quantitation of circulating human irisin by tandem mass spectrometry," Cell Metabolism, vol. 22, no. 4, pp. 734-740, 2015.

[55] F. Norheim, T. M. Langleite, M. Hjorth et al., "The effects of acute and chronic exercise on PGC- $1 \alpha$, irisin and browning of subcutaneous adipose tissue in humans," The FEBS Journal, vol. 281, no. 3, pp. 739-749, 2014.

[56] J. Y. Huh, F. Dincer, E. Mesfum, and C. S. Mantzoros, "Irisin stimulates muscle growth-related genes and regulates adipocyte differentiation and metabolism in humans," International Journal of Obesity, vol. 38, no. 12, pp. 1538-1544, 2014.

[57] R. R. Rao, J. Z. Long, J. P. White et al., "Meteorin-like is a hormone that regulates immune-adipose interactions to increase beige fat thermogenesis," Cell, vol. 157, no. 6, pp. 12791291, 2014.

[58] M. J. Vosselman, J. Hoeks, B. Brans et al., "Low brown adipose tissue activity in endurance-trained compared with lean sedentary men," International Journal of Obesity, vol. 39, no. 12, pp. 1696-1702, 2015.

[59] A. Carrière, Y. Jeanson, S. Berger-Müller et al., "Browning of white adipose cells by intermediate metabolites: an adaptive mechanism to alleviate redox pressure," Diabetes, vol. 63, no. 10, pp. 3253-3265, 2014.

[60] V. Pellegrinelli, C. Rouault, S. Rodriguez-Cuenca et al., "Human adipocytes induce inflammation and atrophy in muscle cells during obesity," Diabetes, vol. 64, no. 9, pp. 3121-3134, 2015.

[61] N. Franck, M. Maris, S. Nalbandian et al., "Knock-down of IL$1 \mathrm{Ra}$ in obese mice decreases liver inflammation and improves insulin sensitivity," PLoS ONE, vol. 9, no. 9, Article ID e107487, 2014.

[62] L. Cron, T. Allen, and M. A. Febbraio, "The role of gp130 receptor cytokines in the regulation of metabolic homeostasis," Journal of Experimental Biology, vol. 219, part 2, pp. 259-265, 2016.

[63] G. J. Tesz, A. Guilherme, K. V. P. Guntur et al., "Tumor necrosis factor $\alpha(\mathrm{TNF} \alpha)$ stimulates Map4k4 expression through TNF $\alpha$ receptor 1 signaling to c-Jun and activating transcription factor 2," The Journal of Biological Chemistry, vol. 282, no. 27, pp. 19302-19312, 2007.

[64] K. D. Nguyen, Y. Qiu, X. Cui et al., "Alternatively activated macrophages produce catecholamines to sustain adaptive thermogenesis," Nature, vol. 480, no. 7375, pp. 104-108, 2011.

[65] J. I. Odegaard, K. Ganeshan, and A. Chawla, "Adipose tissue macrophages: Amicus adipem?" Cell Metabolism, vol. 18, no. 6, pp. 767-768, 2013.

[66] J. E. Heredia, L. Mukundan, F. M. Chen et al., "Type 2 innate signals stimulate fibro/adipogenic progenitors to facilitate muscle regeneration," Cell, vol. 153, no. 2, pp. 376-388, 2013.

[67] A. B. Molofsky, J. C. Nussbaum, H.-E. Liang et al., "Innate lymphoid type 2 cells sustain visceral adipose tissue eosinophils and alternatively activated macrophages," The Journal of Experimental Medicine, vol. 210, no. 3, pp. 535-549, 2013.

[68] J. Osório, "Metabolism: type 2 immunity at the origin of beige adipocytes," Nature Reviews Endocrinology, vol.10, no. 8, p. 443, 2014.

[69] R. R. Ricardo-Gonzalez, A. R. Eagle, J. I. Odegaard et al., "IL-4/STAT6 immune axis regulates peripheral nutrient metabolism and insulin sensitivity," Proceedings of the National Academy of Sciences of the United States of America, vol. 107, no. 52, pp. 22617-22622, 2010.

[70] P. S. Liu, Y. W. Lin, F. H. Burton, and L. N. Wei, "Injecting engineered anti-inflammatory macrophages therapeutically induces white adipose tissue browning and improves diet-induced insulin resistance," Adipocyte, vol. 4, no. 2, pp. 123-128, 2015.

[71] Y. Zhang, P. Yang, R. Cui et al., "Eosinophils reduce chronic inflammation in adipose tissue by secreting Th 2 cytokines and promoting M2 macrophages polarization," International Journal of Endocrinology, vol. 2015, Article ID 565760, 5 pages, 2015.

[72] A. B. Molofsky, F. Van Gool, H.-E. Liang et al., "Interleukin-33 and interferon- $\gamma$ counter-regulate group 2 innate lymphoid cell activation during immune perturbation," Immunity, vol. 43, no. 1, pp. 161-174, 2015.

[73] J. R. Brestoff and D. Artis, "Immune regulation of metabolic homeostasis in health and disease," Cell, vol. 161, no. 1, pp. 146160, 2015.

[74] W. Liu, P. Bi, T. Shan et al., "miR-133a regulates adipocyte browning in vivo," PLoS Genetics, vol. 9, no. 7, Article ID e1003626, 2013.

[75] L. Sun, H. Xie, M. A. Mori et al., "Mir193b-365 is essential for brown fat differentiation," Nature Cell Biology, vol. 13, no. 8, pp. 958-965, 2011.

[76] M. Trajkovski, K. Ahmed, C. C. Esau, and M. Stoffel, "MyomiR133 regulates brown fat differentiation through Prdm16," Nature Cell Biology, vol. 14, no. 12, pp. 1330-1335, 2012.

[77] M. Cioff, M. Vallespinos-Serrano, S. M. Trabulo et al., "MiR-93 controls adiposity via inhibition of Sirt7 and Tbx3," Cell Reports, vol. 12, no. 10, pp. 1594-1605, 2015.

[78] M. Mori, H. Nakagami, G. Rodriguez-Araujo, K. Nimura, and Y. Kaneda, "Essential role for miR-196a in brown adipogenesis of white fat progenitor cells," PLoS Biology, vol. 10, no. 4, Article ID e1001314, 2012.

[79] D. Pan, C. Mao, B. Quattrochi et al., "MicroRNA-378 controls classical brown fat expansion to counteract obesity," Nature Communications, vol. 5, article 4725, 2014.

[80] F. Hu, M. Wang, T. Xiao et al., "miR-30 Promotes Thermogenesis and the Development of Beige Fat by Targeting RIP140," Diabetes, vol. 64, no. 6, pp. 2056-2068, 2015.

[81] T. Fu, S. Seok, S. Choi et al., "MicroRNA 34a inhibits beige and brown fat formation in obesity in part by suppressing adipocyte fibroblast growth factor 21 signaling and SIRT1 function," Molecular and Cellular Biology, vol. 34, no. 22, pp. 4130-4142, 2014.

[82] M. Karbiener, D. F. Pisani, A. Frontini et al., "MicroRNA-26 family is required for human adipogenesis and drives characteristics of brown adipocytes," STEM CELLS, vol. 32, no. 6, pp. 1578-1590, 2014.

[83] J. R. Alvarez-Dominguez, Z. Bai, D. Xu et al., "De novo reconstruction of adipose tissue transcriptomes reveals long noncoding RNA regulators of brown adipocyte development," Cell Metabolism, vol. 21, no. 5, pp. 764-776, 2015.

[84] T. J. Schulz, T. L. Huang, T. T. Tran et al., "Identification of inducible brown adipocyte progenitors residing in skeletal muscle and white fat," Proceedings of the National Academy of Sciences of the United States of America, vol. 108, no. 1, pp. 143148, 2011.

[85] Y.-H. Tseng, E. Kokkotou, T. J. Schulz et al., "New role of bone morphogenetic protein 7 in brown adipogenesis and energy expenditure," Nature, vol. 454, no. 7207, pp. 1000-1004, 2008. 
[86] A. J. Whittle, S. Carobbio, L. Martins et al., "BMP8B increases brown adipose tissue thermogenesis through both central and peripheral actions," Cell, vol. 149, no. 4, pp. 871-885, 2012.

[87] F. M. Fisher, S. Kleiner, N. Douris et al., "FGF21 regulates PGC- $1 \alpha$ and browning of white adipose tissues in adaptive thermogenesis," Genes \& Development, vol. 26, no. 3, pp. 271281, 2012.

[88] B. Emanuelli, S. G. Vienberg, G. Smyth et al., "Interplay between FGF21 and insulin action in the liver regulates metabolism," The Journal of Clinical Investigation, vol. 124, no. 2, pp. 515-527, 2014.

[89] A. Vegiopoulos, K. Müller-Decker, D. Strzoda et al., "Cyclooxygenase- 2 controls energy homeostasis in mice by de novo recruitment of brown adipocytes," Science, vol. 328, no. 5982, pp. 1158-1161, 2010.

[90] I. Bayindir, R. Babaeikelishomi, S. Kocanova et al., "Transcriptional pathways in cPGI2-induced adipocyte progenitor activation for browning," Frontiers in Endocrinology, vol. 6, article 129, 2015.

[91] M. Bordicchia, D. Liu, E.-Z. Amri et al., "Cardiac natriuretic peptides act via 338 MAPK to induce the brown fat thermogenic program in mouse and human adipocytes," The Journal of Clinical Investigation, vol. 122, no. 3, pp. 1022-1036, 2012.

[92] V. García-Alonso, C. López-Vicario, E. Titos et al., "Coordinate functional regulation between microsomal prostaglandin $\mathrm{E}$ synthase-1 (mPGES-1) and peroxisome proliferator-activated receptor $\gamma(\operatorname{PPAR} \gamma)$ in the conversion of white-to-brown adipocytes," The Journal of Biological Chemistry, vol. 288, no. 39, pp. 28230-28242, 2013.

[93] A. Zinn, S. Felson, E. Fisher, and A. Schwartzbard, "Reassessing the cardiovascular risks and benefits of thiazolidinediones," Clinical Cardiology, vol. 31, no. 9, pp. 397-403, 2008.

[94] A. Loft, I. Forss, M. S. Siersbæk et al., "Browning of human adipocytes requires KLF11 and reprogramming of PPAR $\gamma$ superenhancers," Genes \& Development, vol. 29, no. 1, pp. 7-22, 2015.

[95] A. M. DePaoli, L. S. Higgins, R. R. Henry, C. Mantzoros, and F. L. Dunn, "Can a selective PPAR $\gamma$ modulator improve glycemic control in patients with type 2 diabetes with fewer side effects compared with pioglitazone?" Diabetes Care, vol. 37, no. 7, pp. 1918-1923, 2014.

[96] E. Pino, H. Wang, M. E. McDonald, L. Qiang, and S. R. Farmer, "Roles for peroxisome proliferator-activated receptor $\gamma(\operatorname{PPAR} \gamma)$ and PPAR $\gamma$ coactivators $1 \alpha$ and $1 \beta$ in regulating response of white and brown adipocytes to hypoxia," The Journal of Biological Chemistry, vol. 287, no. 22, pp. 18351-18358, 2012.

[97] C.-S. Lai, M.-L. Tsai, V. Badmaev, M. Jimenez, C.-T. Ho, and M.H. Pan, "Xanthigen suppresses preadipocyte differentiation and adipogenesis through down-regulation of PPAR $\gamma$ and C/EBPs and modulation of SIRT-1, AMPK, and FoxO pathways," Journal of Agricultural and Food Chemistry, vol. 60, no. 4, pp. 1094-1101, 2012.

[98] H. Ohno, K. Shinoda, B. M. Spiegelman, and S. Kajimura, "PPAR $\gamma$ agonists induce a white-to-brown fat conversion through stabilization of PRDM16 protein," Cell Metabolism, vol. 15, no. 3, pp. 395-404, 2012.

[99] M.-J. Obregon, "Adipose tissues and thyroid hormones," Frontiers in Physiology, vol. 5, article 479, 2014.

[100] F. Lizcano and G. Guzmán, "Estrogen deficiency and the origin of obesity during menopause," BioMed Research International, vol. 2014, Article ID 757461, 11 pages, 2014.
[101] M. D. Cardamone, B. Tanasa, M. Chan et al., "GPS2/KDM4A pioneering activity regulates promoter-specific recruitment of PPAR $\gamma$," Cell Reports, vol. 8, no. 1, pp. 163-176, 2014.

[102] F. Lizcano, C. Romero, and D. Vargas, "Regulation of adipogenesis by nuclear receptor PPAR $\gamma$ is modulated by the histone demethylase JMJD2C," Genetics and Molecular Biology, vol. 34, no. 1, pp. 19-24, 2011.

[103] Y. Abe, R. Rozqie, Y. Matsumura et al., "JMJD1A is a signalsensing scaffold that regulates acute chromatin dynamics via SWI/SNF association for thermogenesis," Nature Communications, vol. 6, article 7052, 2015.

[104] T. Inagaki, M. Tachibana, K. Magoori et al., "Obesity and metabolic syndrome in histone demethylase JHDM2a-deficient mice," Genes to Cells, vol. 14, no. 8, pp. 991-1001, 2009.

[105] K. Tateishi, Y. Okada, E. M. Kallin, and Y. Zhang, "Role of Jhdm $2 \mathrm{a}$ in regulating metabolic gene expression and obesity resistance," Nature, vol. 458, no. 7239, pp. 757-761, 2009.

[106] H. Ohno, K. Shinoda, K. Ohyama, L. Z. Sharp, and S. Kajimura, "EHMT1 controls brown adipose cell fate and thermogenesis through the PRDM16 complex," Nature, vol. 504, no. 7478, pp. 163-167, 2013.

[107] V. Cormier-Daire, F. Molinari, M. Rio et al., "Cryptic terminal deletion of chromosome 9q34: a novel cause of syndromic obesity in childhood?" Journal of Medical Genetics, vol. 40, no. 4, pp. 300-303, 2003.

[108] G. Nagano, H. Ohno, K. Oki et al., "Activation of classical brown adipocytes in the adult human perirenal depot is highly correlated with PRDM16-EHMT1 complex expression," PLoS ONE, vol. 10, no. 3, Article ID e0122584, 2015.

[109] F. Li, R. Wu, X. Cui et al., "Histone deacetylase 1 (HDAC1) negatively regulates thermogenic program in brown adipocytes via coordinated regulation of histone H3 Lysine 27 (H3K27) deacetylation and methylation," The Journal of Biological Chemistry, vol. 291, no. 9, pp. 4523-4536, 2016.

[110] L. Zha, F. Li, R. Wu et al., "The histone demethylase UTX promotes brown adipocyte thermogenic program via coordinated regulation of $\mathrm{H} 3 \mathrm{~K} 27$ demethylation and acetylation," The Journal of Biological Chemistry, vol. 290, no. 41, pp. 25151-25163, 2015.

[111] S. C. Kang, S. K. Kim, J. C. Chai et al., "Transcriptomic profiling and $\mathrm{H} 3 \mathrm{~K} 27 \mathrm{me} 3$ distribution reveal both demethylasedependent and independent regulation of developmental gene transcription in cell differentiation," PLOS ONE, vol. 10, no. 8, Article ID 0135276, 2015.

[112] S. Flowers, F. Xu, and E. Moran, "Cooperative activation of tissue-specific genes by pRB and E2F1," Cancer Research, vol. 73, no. 7, pp. 2150-2158, 2013.

[113] E. Calo, J. A. Quintero-Estades, P. S. Danielian, S. Nedelcu, S. D. Berman, and J. A. Lees, "Rb regulates fate choice and lineage commitment in vivo," Nature, vol. 466, no. 7310, pp. 1110-1114, 2010.

[114] J. Auffret, S. Viengchareun, N. Carré et al., "Beige differentiation of adipose depots in mice lacking prolactin receptor protects against high-fat-diet-induced obesity," The FASEB Journal, vol. 26, no. 9, pp. 3728-3737, 2012.

[115] M. De Sousa, D. P. Porras, C. G. R. Perry, P. Seale, and A. Scimè, "P107 is a crucial regulator for determining the adipocyte lineage fate choices of stem cells," STEM CELLS, vol. 32, no. 5, pp. 1323-1336, 2014.

[116] Y. D. Tchoukalova, S. B. Votruba, T. Tchkonia, N. Giorgadze, J. L. Kirkland, and M. D. Jensen, "Regional differences in cellular 
mechanisms of adipose tissue gain with overfeeding," Proceedings of the National Academy of Sciences of the United States of America, vol. 107, no. 42, pp. 18226-18231, 2010.

[117] K. L. Spalding, E. Arner, P. O. Westermark et al., "Dynamics of fat cell turnover in humans," Nature, vol. 453, no. 7196, pp. 783787, 2008.

[118] C. M. Kusminski, P. E. Bickel, and P. E. Scherer, "Targeting adipose tissue in the treatment of obesity-associated diabetes," Nature Reviews Drug Discovery, 2016.

[119] H. Xu, G. T. Barnes, Q. Yang et al., "Chronic inflammation in fat plays a crucial role in the development of obesity-related insulin resistance," The Journal of Clinical Investigation, vol. 112, no. 12, pp. 1821-1830, 2003.

[120] T. Yoneshiro, S. Aita, M. Matsushita et al., "Recruited brown adipose tissue as an antiobesity agent in humans," Journal of Clinical Investigation, vol. 123, no. 8, pp. 3404-3408, 2013.

[121] M. Chondronikola, E. Volpi, E. Børsheim et al., "Brown adipose tissue improves whole-body glucose homeostasis and insulin sensitivity in humans," Diabetes, vol. 63, no. 12, pp. 4089-4099, 2014.

[122] X.-R. Peng, P. Gennemark, G. O’Mahony, and S. Bartesaghi, "Unlock the thermogenic potential of adipose tissue: pharmacological modulation and implications for treatment of diabetes and obesity," Frontiers in Endocrinology, vol. 6, article 174, 2015.

[123] L. Kazak, E. T. Chouchani, M. P. Jedrychowski et al., "A creatinedriven substrate cycle enhances energy expenditure and thermogenesis in beige fat," Cell, vol. 163, no. 3, pp. 643-655, 2015. 


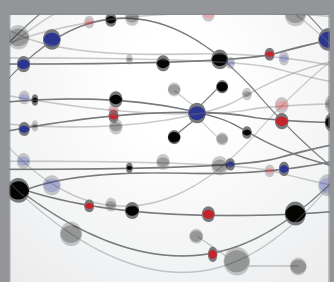

The Scientific World Journal
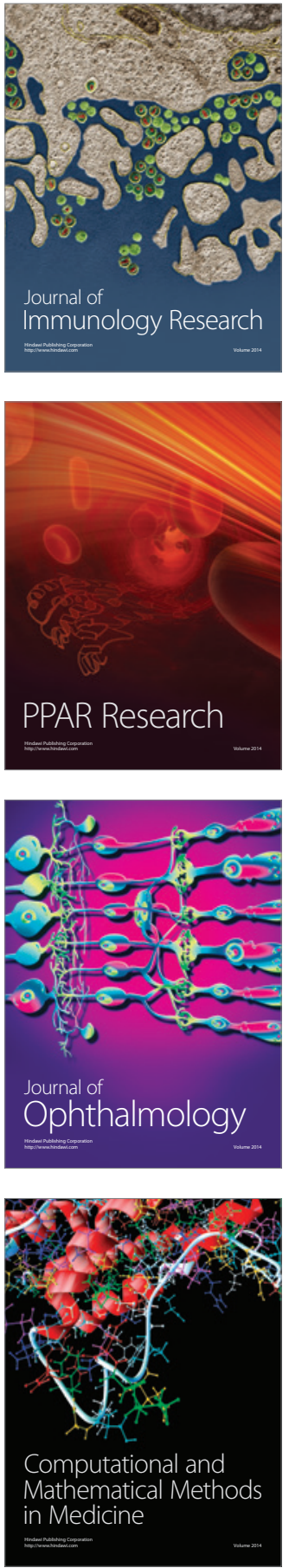

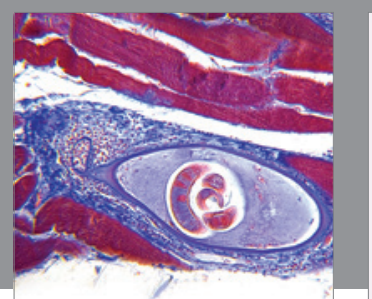

Gastroenterology Research and Practice

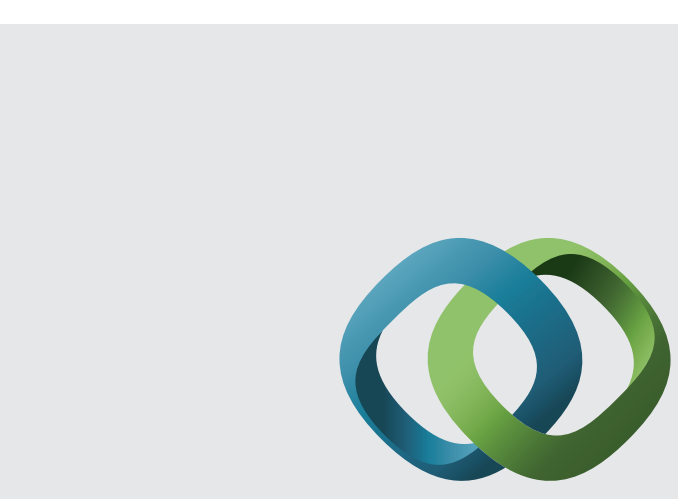

\section{Hindawi}

Submit your manuscripts at

http://www.hindawi.com
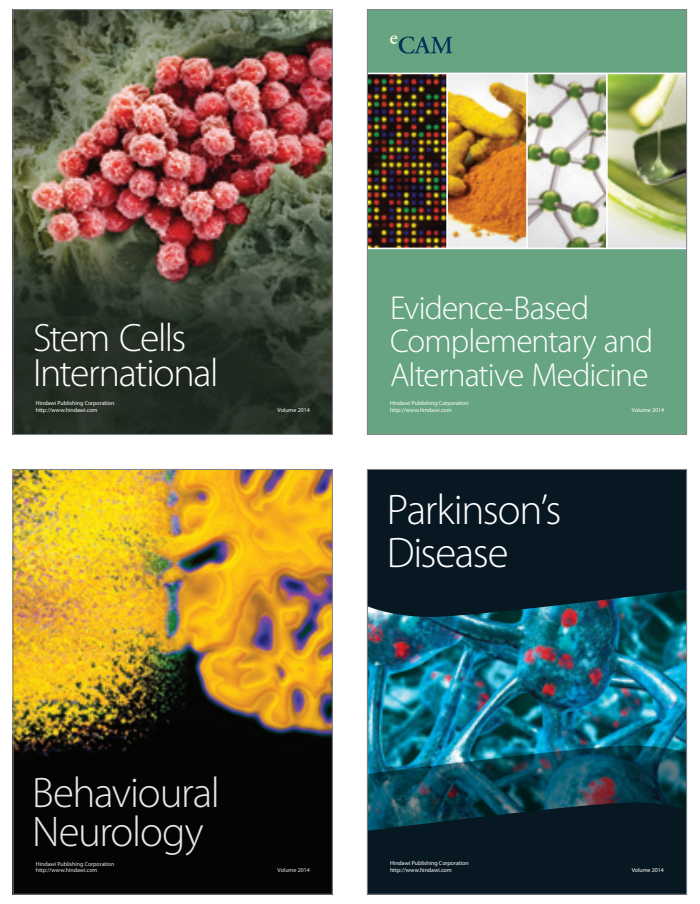
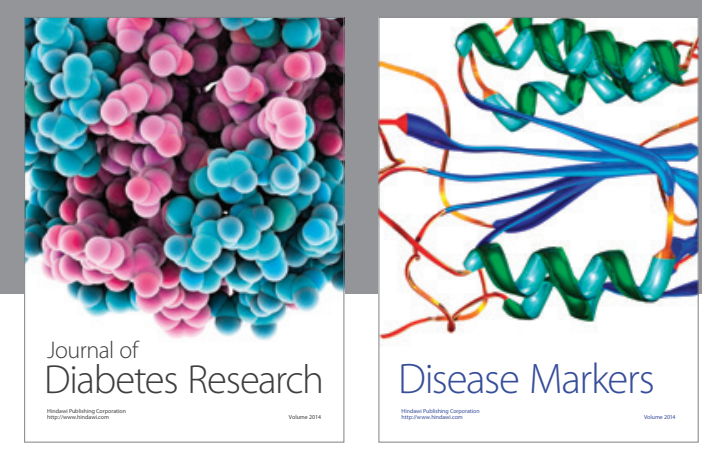

Disease Markers
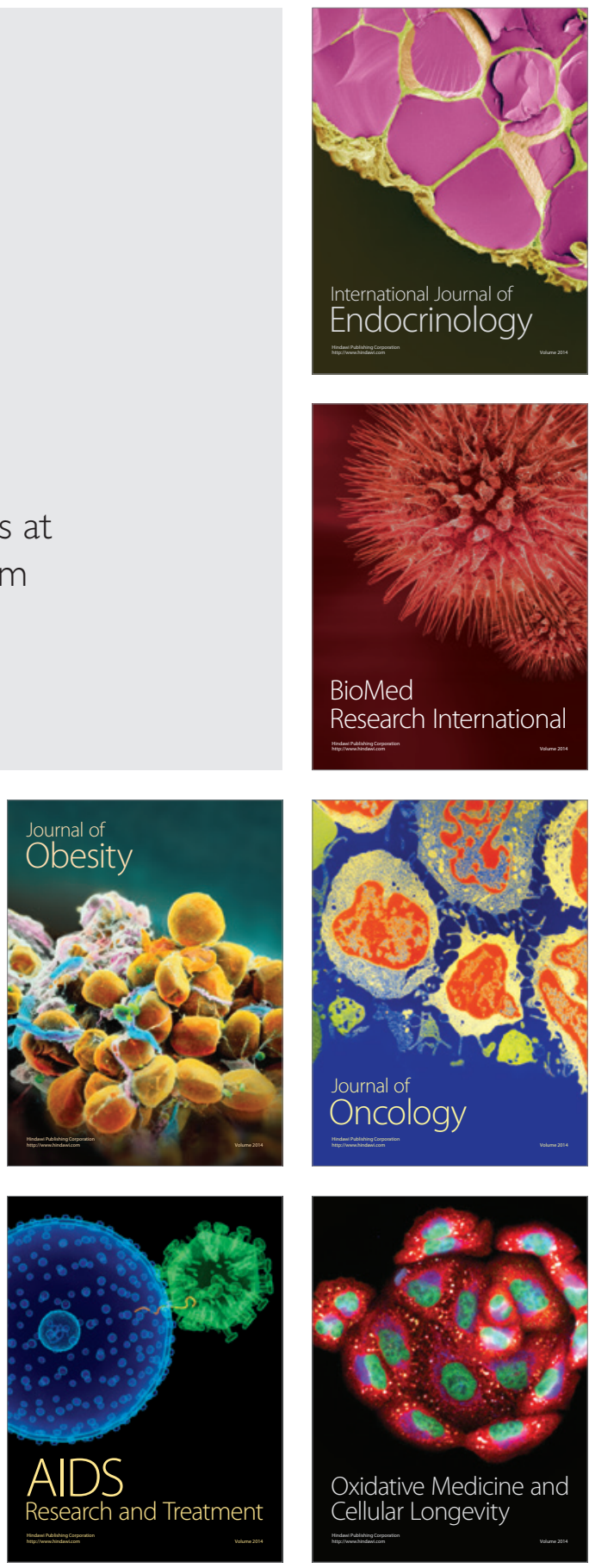